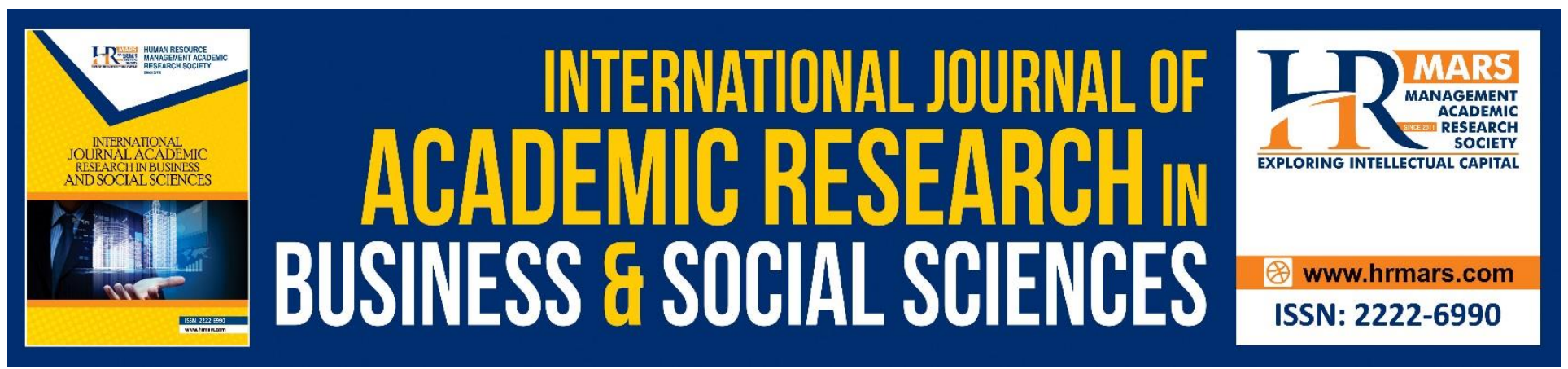

\title{
Application of Pesticides Act 1974 In Protecting Community and Environment Health in Malaysia From the Exposure of Pesticides
}

Haliza Abdul Rahman

To Link this Article: http://dx.doi.org/10.6007/IJARBSS/v11-i15/10641

DOI:10.6007/IJARBSS/v11-i15/10641

Received: 02 May 2021, Revised: 28 May 2021, Accepted: 25 June 2021

Published Online: 24 July 2021

In-Text Citation: (Rahman, 2021)

To Cite this Article: Rahman, H. A. (2021). Application of Pesticides Act 1974 In Protecting Community and Environment Health in Malaysia From the Exposure of Pesticides. International Journal of Academic Research in Business and Social Sciences, 11(185), 144-153.

Copyright: (C) 2021 The Author(s)

Published by Human Resource Management Academic Research Society (www.hrmars.com)

This article is published under the Creative Commons Attribution (CC BY 4.0) license. Anyone may reproduce, distribute, translate and create derivative works of this article (for both commercial and non-commercial purposes), subject to full attribution to the original publication and authors. The full terms of this license may be seen

at: http://creativecommons.org/licences/by/4.0/legalcode

Special Issue: Empowering Youth and Community Wellbeing for Sustainable Development, 2021, Pg. 144 - 153

http://hrmars.com/index.php/pages/detail/IJARBSS

JOURNAL HOMEPAGE

Full Terms \& Conditions of access and use can be found at http://hrmars.com/index.php/pages/detail/publication-ethics 


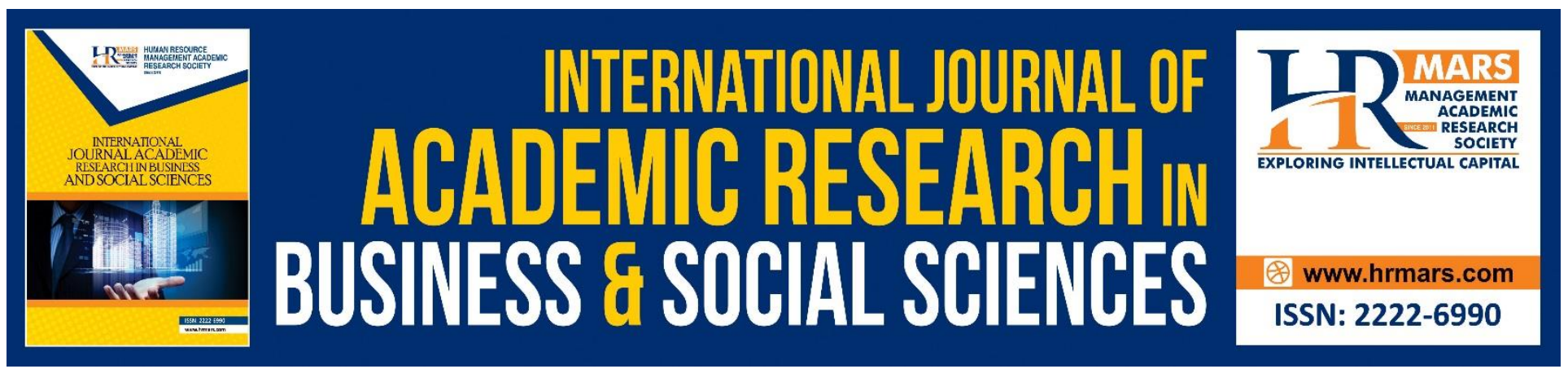

\title{
Application of Pesticides Act 1974 In Protecting Community and Environment Health in Malaysia From the Exposure of Pesticides
}

\author{
Haliza Abdul Rahman ${ }^{1,2}$ \\ ${ }^{1}$ Institute for Social Sciences Studies (IPSAS), Putra InfoPort, Universiti Putra Malaysia, 43400 \\ UPM Serdang, Selangor, Malaysia, ${ }^{2}$ Department of Environmental and Occupational Health, \\ Faculty of Medicine and Health Sciences, Universiti Putra Malaysia, 43400 UPM Serdang, \\ Selangor, Malaysia \\ Email: dr.haliza@upm.edu.my
}

\begin{abstract}
Introduction: Pesticides are used to boost agricultural production in Malaysian farms in an effort to reduce or eliminate yield losses and maintain high produce quality. The high toxicity of these pesticides can be detrimental to public and environmental health. Thus, the issues of dumping of illegal pesticides in the market and being used by the farmer becoming a growing concern. To tackle this issues, Pesticides Act 1974 (Act 149) is enacted to regulate various aspects related to pesticide and applies throughout Malaysia. The Act covers the management of all pesticides and other chemicals used in agriculture. This paper discussed on the beneficial of Pesticide Act 1974 and elaborates of its strengthen and weaknesses. Secondary data are collected with regard to "Pesticides Act 1974", "strengthen" and "weaknesses" of this act to protect community and environment. Pesticide poisoning in Malaysia is become the second major cause of poisoning group after pharmaceuticals. Thus, this Act has a strict control of the presence of pesticides in food, which the Board has the power to cancel the registration if it is found that the pesticides contain adverse effects on human beings, animals, plants, fruits or property due to their toxicity and inefficacy. On the other side, this Act still not effectively controlled the unregistered, smuggle and banned pesticide. The current Pesticides Act 1974 can do better amendment in future in order to tackle the unregistered pesticides issues by making more improvement to this Act so that the problems can be reduce or eliminate. In order to increase penalties and impose mandatory imprisonment and fines on the culprit, there must be a review of the Act to guarantee that the damage involved will be punished as the serious crime that it is.
\end{abstract}

Keywords: Pesticide Exposure, Toxicity, Damage, Human and Environmental Health, Responsibility to Control 


\section{Introduction}

Agriculture is an important occupation in Malaysia that generates a major portion of the national revenue. Similar to the rest of the world, pesticides are used to boost agricultural production in Malaysian farms (Sulaiman et al., 2019) which farming practices involve the use of pesticides on various vegetables, fruits, paddy, rubber and palm oil plantations (Bakar, 2009). Pesticide can be defined as any substance or chemical that being used by people to destroy the harmful living things (Higgins and Burns, 1975). Normally, pesticides are chemicals used for controlling pests and weeds, and include herbicides, insecticide, fungicide, antimicrobials, rodent repellants (Hillock, 2012) in an effort to reduce or eliminate yield losses and maintain high produce quality. It is used in liquid form, concentrated, powder, dust, particle and aerosol and fog. The pesticide that has been spurted will move and transfer to the environment through water, wind and absorption process. It can be transferred thousands miles away and can be infiltrated into meat, milk, human blood, animal and plants which can stay longer depends on the pesticides. Some can stay as residue within hours, week, month and year (Fuad et al., 2012).

According to Knoema (2019), as of 2016, pesticide use in Malaysia reached at level of 49199.43 tonnes of active ingredients, with total use of $5.9 \mathrm{~kg} / \mathrm{ha}$ of crop land. Import value was estimated to be worth US\$202572.48 while the export value was worth at US\$68 424.65. As stated by the Malaysian Department of Agriculture (2020), the use of pesticides in Malaysia is regulated, and the common pesticides used in agriculture are the organophosphates, the pyrethroids, glyphosate and 2,4-D-dimethylammonium. Because of that, the issues of dumping of illegal pesticides in the market and being used by the farmer becoming a growing concern. The quality of the pesticides has become the disputed matter among the user. One study by Bakand et al (2012) examined the market trend where the demand for supply of pest-free and nice-looking products has led to misuse and overuse of these chemicals beyond the recommended levels.

The high toxicity of these pesticides can be detrimental to public health when exposed either through consumption, dermal contact, or inhalation (Kim et al, 2017). Thus, pesticide poisoning is a global health problem, and its progressive deterioration is a major cause of concern (Bertolote, 2006). The World Health Organization (WHO) has identified pesticide poisoning as a leading cause of public health problem which causes significant morbidity and mortality. According to the Centre for Science and Environment, a public interest research and advocacy organization based in New Delhi, high levels of pesticide residues can be toxic enough to cause long-term cancer, damage to the nervous and reproductive systems, birth defects, and severe disruption of the immune system. Moreover, Praneet et al (2013) showed that regular exposure to pesticides can cause serious health issues such as asthma, sperm count reduction, decline in sperm quality, psoriasis, and dermatitis. Furthermore, available information raises concerns regarding the long-term effects of pesticides on microorganisms, primary producers, and invertebrates of importance to soil fertility, predators of rice pests and vectors, and microbial metabolism of pesticides (Roger et al., 1994). Greene and Pohanish (2005) has shown that less than $0.1 \%$ of applied pesticide actually reach the target pest, with the remaining spreading into the environment, and consequently effecting the farmers, consumers, air, soil, and water.

In short, overused and mismanagement of pesticides by farmers not only effecting human health but slowly disturbs the ecosystem of living things and effects the interaction of human, animal and plants 
in continuing well-being life. Although pesticides are developed through very strict regulation processes to function with reasonable certainty and have minimal impact on human health and the environment, serious concerns have been raised about health risks resulting from occupational exposure and from residues in food and drinking water

Because of the negative impacts especially to the human health, The World Health Organization (WHO) has formulated a Recommended Classification of Pesticides by Hazard by categorizing pesticides according to their health hazard, ranging from "extremely hazardous" to "unlikely to present acute hazard". This is a very useful tool, especially for developing countries, for eliminating extremely toxic pesticides (WHO, 2016). Malaysia should beneficial that and as well follow the example of Singapore's stringent checks on food and vegetables before they are allowed to enter the publics (New Straits Times, 25 December 2018), as efficiency enforce the Pesticides Act (Act 149) throughout the country. Malaysia have Pesticide Act 1974 as the principal legislation to regulate the pesticide (Agrochemical, 2017). The application of this act in order to protect human and environmental health from pesticide exposure are through their regulation and sections.

\section{Methodology}

This review paper involved with secondary data which are collected from journal, proceedings, books and social media with referring to the Pesticides Act 1974.

\section{Results and Discussion}

Pesticides Act 1974 (Act 149)

According to the Section 2(1) of Pesticides Act 1974, pesticide is defined as "any substance that contains an active ingredient or any preparation, mixture or material that contains any one or more of the active ingredients as one of its constituents but does not include contaminated food or any article listed in the Second Schedule". Pesticides are divided into two groups, which are household pesticides and agricultural pesticides. The household pesticides consist of household insecticides and rodenticides while agricultural pesticides consist of various formulations of insecticides, herbicides and fungicides. In addition, pesticide-induced health problems can be categorized into intentional, accidental and occupational (Bakar, 2009).

Pesticides Act 1974 (Act 149) is law enacted to regulate various aspects related to pesticide, this act applies throughout Malaysia. The Pesticides Act 1974 is the principle legislation covers the management of all pesticides and other chemicals used in agriculture. The Act consists of the following Parts: Preliminary (I); The Pesticides board (II); Control of importation and manufacture of pesticides by registration and permit (III); Control of manufacture, sale and storage of pesticides by licensing (IV); Control of presence of pesticides in food (V); Death and injury occasioned by pesticides (VI); Enforcement (VII); Analysis (VIII); Proceedings (IX); General (X); Amendment, repeal, and saving of related laws $(\mathrm{XI})$.

The Pesticides Board is set up to implement the Act under the jurisdiction of the Ministry of Agriculture comprised of members from relevant government agencies. The Pesticide Control Division of the Department of Agriculture was entrusted with the task of providing the secretariat to the Board for the implementation of the act. There are presently seven subsidiary legislations being enforced in the area such as registration, importation for research and education purposes, labeling, 
licensing for sale and storage for sale, highly toxic pesticides, advertisement, and pest control operators (Summer, 2017). The following data/information needs to be submitted to the Board for evaluation at registration process: Data on product chemistry, Data on bio efficacy, Data on mammalian toxicology, Data on ecotoxicology, Data on environmental fate, Data on residue in food crops, Data on safe handling and Packaging and labeling.

The Malaysian Pesticide Board has classified all registered pesticides into four classes according to their level of toxicity to human beings. These classifications appear as color bands at the bottom of a pesticide label. Class 1 (black band for Class 1a which is very highly poisonous and red band for Class $1 \mathrm{~b}$ together with a skull and crossbones symbol) is highly poisonous and is usually only used by trained persons. Class 2 in yellow band is classified as poisonous. Class 3 is labeled as harmful and the least toxic group is classified in Class 4.

Several amendments have been made to Pesticides Act 1974 such as the control of importation of pesticides as registration samples and control of possession or use of unregistered pesticides, and imposing of penalties for all offences. Other related regulations on the management of pesticides are the Environmental Quality Act 1974, the Food Act 1983 and Occupational Safety and Health Act 1994. The primary objective of Environmental Quality Act 1974 is to control the discharge of chemical and industrial wastes including pesticides into the environment, so that there will be no adverse effects on human health and the environment. On the other hand, the Food Act 1983 prescribes the maximum residue levels of certain pesticides in food. While, the Occupational Safety and Health Act 1994 responsible for administering, managing, and enforcing legislation related to occupational safety and health of workers at work (Summer, 2017).

\section{How This Act Protecting the Community and Environmental Health?}

The application of Pesticides Act 1974 can help in protecting the community and environmental health from the exposure of pesticides. First, the establishment of Pesticides Board in the Act helps managing and controlling the use of pesticides in Malaysia. This is because, as stated in section 3, the Board includes 14 members of related agencies including Director General of Agriculture, Chemistry, Malaysian Rubber Board, etc. Besides, the objective of the establishment of the Board is to decide on policies regarding to pesticides use. the members of the Board are those with specialties in their own field which can help assessing the rules and regulations for a better enforcement. Besides, the Board duty is also to evaluate the use of the pesticides in market to make sure that there are no adverse effects to the human or the environment.

Next, Part 3 of the Pesticides Act explains about the registration and permit to control its sale, the importation and manufacture of pesticides. This part is very important to make sure the use of pesticides in this country is under controlled. For example, section 7(1) states that "A person desiring to import or manufacture a pesticide shall apply to the Board in the prescribed manner for registration of the pesticide". This means that every pesticide used in the country is being assessed first before being sold. Stiffer penalties would be imposed on those who gave false information when selling the pesticides and those who conducted experiment and research on unregistered pesticides without permits. Besides, subsection 2 further explains about the information that need to be submitted to register the pesticide. For instance, the information that need to be submitted includes common name of the pesticide if available, trade name, chemical name, structural formula, and the 
name and concentration of each active ingredient in the pesticide. In addition, the Board has the power to cancel the registration if it is found that the pesticides contain adverse effects on human beings, animals, plants, fruits or property due to their toxicity and inefficacy. In this term the approval is depend on the investigation that pesticide board carry out. I think it is one of the way of this Act to protect human and environment from pesticide exposure, because from this we know the registration of pesticides are through a detail investigation. Thus if it contains much toxicity and harmful, board will not grant their registration. If they contravene under section 20(4) they will liable to an imprisonment for 3 years and fine RM10,000 or imprisonment 20 years and fine RM 20,000 or both.

Third, the Pesticides Act 1974 also controls the use of pesticides by licensing. For example, the manufacture that produce the pesticides. According to section 15(1), "A person $n$ desiring to manufacture a pesticide shall apply to the Board in the prescribed

manner and accompanied with the prescribed application fee, for a license to manufacture the pesticide". Thus, licensed is required for a person who wants to sale, manufacture and storage pesticide. A person who has licensed means that they have fulfilled all the requirement, so they must know the risk and the toxicity of the pesticide (Shaari and Ali, 2015). Under the Pesticides Act, Regulation of Pest Controller was made to make sure that the pest controller has license to make sure the effectiveness of pest control and does not pose danger to human and environment. Thus this part can mitigate the impact of pesticide to environment and human health. In my point of view, the Pesticides Act has controlled the manufacturing of pesticides to make sure that no one can easily produce the chemicals. Besides of the manufacturer, the person who controls the pesticides also needs to have license before they can operate.

In addition, the Pesticides Act also control how the manufacturer labelled the pesticides. This is important so that the users can see the relevant information about the chemicals such as the common name, usage, structural formula, bane code, color and safety phrase by pesticide classification as stated in Regulation 4. Besides, a pesticide label should have a warning or caution sign to prevent the risk to humans, animals, and environment. In the Pesticides Regulation (labelling) 1984, it has specified the different classes of warning signs as stated in Regulation 4(j). Besides, the regulation also state the translation of standard words use in the labelling in Bahasa Malaysia and English. Besides, the warning signs also are translated into six different languages since Malaysia is a multiracial country. Thus, the labelling of pesticides can help to ensure that all registered pesticides are labeled in accordance with good labeling practices

Lastly, the Act has a strict control of the presence of pesticides in food. This regulation is prohibited the addition and treatment of pesticide to any kind of food. I think this part is the major point from this act because we as a human we can't consume any kind of pesticide, because it is harmful and also carcinogenic toward human body. Under Part 5 of the Act, section 21 states that "The Minister may, after consulting the Board and the Minister responsible for health services, make regulations to prohibit the addition to or the use or presence in food or any specified kind thereof; or the treatment of food or any specified kind". Furthermore, an authorized officer may enter and inspect any place in which he or she believes that there is any food intended for sale, and seize, or detain such food that appears or is believed to be contaminated food as stated in section 22 . After that they have a power under section 23(1) to take a sample and then can run an analysis toward the food. This part is really 
useful to prevent the existence of pesticide in human food and reduce the impact of pesticide to human health. Besides, section 25 states that a person who sells contaminated food is considered committing an offense. Thus, it is important for those who sells food to ensure that there is no contamination with pesticides, or else they will be committing an offense since the act give rights the authorized officer, and anyone who bought the food to ask for analysis. They can also stop any vehicle that he suspects to bring an unregistered pesticide. From this they are simultaneously mitigate the illegal sale or usage of the pesticide and also protect the environment and human from its exposure.

\section{Weaknesses of Pesticide Act 1974}

On the other side, this Act still not effectively controlled the unregistered, smuggle and banned pesticide. Malaysia pesticide board have a monitor system on four pesticides that has been registered. However, they don't have the monitor system for the remaining pesticides that have never been registered and used (Ramachandra and Mourin, 2006). On 2018, Agriculture directorgeneral Datuk Jamal Harizan Yang Razali said that, there are a movement of unregistered pesticide in Malaysia that might be threaten the country's food safety (Bernama, 2018). Not only harm to food safety in Malaysia, it also harms the farmers who has been exposed to it. Back from 27th November 2018 to 29th November 2018, five premises in Kinta and Pengkalan Hulu, Perak were raided by the Department of Pesticides and Fertiliser Control. They found many unregistered pesticides worth more than RM1 million (The Sun Daily, 2018).

Despite, referred to Bernama (2018), there has been an issue of illegal pesticide use in Cameron Highlands. The effect of the illegal pesticides has been rising the risk and has been threatening the health and environmental health. For an example, for many years Cameron Highlands has gained a reputation for its hazardous pesticide use and evidence of the use of prohibited and illegal pesticides is of very serious concern. According to The Star (2019), together with research carried out by Universiti Kebangsaan Malaysia and Universiti Teknologi Malaysia, the media reports indicated that lindane and DDT, which are banned in the country are suspected of being used in Cameron Highlands farms and plantations. Both of the pesticides also known as persistent organic pollutants (POPs) are organic compounds with a long half-life and gradual physical, chemical and biological degradation in the environment. According to Ramakrishnan Ramasamy, the regional Environmental Awareness of Cameron Highland President, the illegal pesticides has been used and sold publicly (New Straits Times, 2018). Even though after reporting, there has been no actions taken to handle the selling of the illegal pesticides. The person who was selling the illegal pesticides were not punished for the offence. This proves that the act has not really effectively controlled the use of unregistered pesticide in Malaysia as there are many issues and cases occurring because of the unregistered pesticides.

Some farmers also prefer illegal pesticide because of the cheaper price and much stronger that common pesticide. This is evidenced by the activity of importing unregistered products from neighboring countries to this country, especially among farmers and gardeners in the north of peninsular Malaysia. This is because, this product has been in high demand because it is sold 40 percent cheaper (Bernama, 2018). Furthermore, farmers tend to overuse or misused pesticide due to lack of information on pesticide use. As example, Ali et al. (2018) stated that one-third of farmers in their research have negative attitude and was willing to break the rules if an attack by insect or pests occurred. It shows that, there is a lack of general knowledge on management strategies like use of trapping devices, crop rotation, sanitation, bio pesticides, and biological control agents used in an 
Integrated Pest Management (IPM) approach (DOA, 2009) among the farmers. In most previous literature by Abadi (2018) and Rezaei et al. (2018), inappropriate use of pesticides in most cases has been linked to farmers' weak knowledge and inappropriate attitudes towards using pesticide.

Moreover, there are some people that still persistence to bring an unregistered pesticide which quite poisonous, even though they have been charged to a fine. The poisonous of pesticide lead to the public health issues in Malaysia, that contributes to significant morbidity and mortality. According to Kamaruzaman et al (2020), pesticide poisoning in Malaysia is become the second major cause of poisoning group after pharmaceuticals. The pesticide poisonous was prevelance to a male with the average incident 4.21 per 100000 meanwhile female 2.54 per 100000 population. Thus, government need to take more action toward this unregistered pesticides issues towards Pesticide Act 1974 still can't control the issues properly. Despite there are some policies that provide the basis for passing legislation and regulations to overcome the possess or use of unregistered pesticides and unapproved use of pesticides but still the policies are not properly implemented and effective due to some causes and problems such as corruption and lack of continuity in government policies.

\section{Conclusion and Recommendation}

Instead of the beneficial enacted of this Act, the Pesticide Act should be able to obstruct any importation of unregistered pesticides that may enter in any form. Firmer penalties should be given to people who are caught in usage of unregistered pesticides without permits so that the allegation will not repeat in the future. Higher penalties of fees will make people more cautious and careful of what pesticides are being imported. Authority should narrow down the flow of pesticides to Malaysia and every pesticide that are imported should be examined more strictly to prevent repackaging. Most unregistered pesticides were brought into Malaysia from the neighboring countries. Therefore, to overcome these issues, the country's borders must be kept secure so that there would not be any illegal smuggling of the pesticides and other items. Next, unregistered pesticides are unable to enter Malaysia if this country has very strict immigration rules.

Act also is not effective because maybe the amount to do inspection regularly is not enough especially in rural areas. This problem can be overcome by increasing the amount of inspection often especially in targeted rural areas that usually use this illegal pesticide and increase the number of person that do the inspection so that action can be taken quickly to avoid further pollution in future. On the other hand, due to many components that required to register pesticide, people especially farmers will think that the procedure to register is difficult and need to use a lot of money and time so they take easy way by selling or use unregistered pesticides due to the price that cheaper than the registered pesticides. Some improvement that can suggest to improve this Act is maybe by making the procedure to register the pesticides easier, reduce the cost for the registration to cheaper and make the place for registration of this pesticides nearer by their places especially for rural areas villagers.

Some more, to controlled unregistered pesticides in Malaysia, this Act only focus especially about the pesticides and the sellers. There is one problem that appears such as the impact of unregistered pesticides become more critical when there are some foreign workers that often cannot read labels and do not disperse the pesticides in the right concentration. There is no clear Act to declare who is the person that can use the pesticides or only people who get proper training can use the pesticides. Thus, the suggestion to improve this Pesticides Act 1974 is maybe in future there must be one section 
for people that who can only handle this pesticide must have proper training or seminar otherwise they cannot handle this pesticide and even can get penalties. Government also need to increase the awareness among people in Malaysia mainly to farmers, for example do a campaign and tell detailed about what type of pesticide that legal and type of pesticide that has been banned or unregistered in Malaysia.

In conclusion, the current Pesticides Act 1974 can do better amendment in future in order to tackle the unregistered pesticides issues by making more improvement to this Act so that the problems can be reduce or eliminate. Hence, in order to increase penalties and impose mandatory imprisonment and fines on the culprit, there must be a review of the Act. This is to guarantee that the damage involved will be punished as the serious crime that it is.

\section{Declaration}

I declare that this manuscript is my original work and it is submitted for first publication to HRMAS. The manuscript has not been published and is not being submitted or considered for publication elsewhere. The text, illustrations, or any other materials included in the manuscript contains no violation of any existing copyright and does not infringe any rights of third parties.

\section{References}

Abadi, B. (2018). The determinants of cucumber farmers' pesticide use behaviour in Central Iran: implications for the pesticide use management. Journal of Cleaner Production, 205: 10691081.

Ali, J., Yusof, N., and Aziz, F. S. A. (2018). Factors influencing farmer's perceptions and behavior towards pesticide use in Malaysia. International Journal of Social Economics, 45(5): 776-792.

Bakar, B. B. (2009). The Malaysian agricultural industry in the new millennium: Issues and challenges.

Bakand, S., Dehghani, J., Gohari, M. Mosaddegh, M. H., and Mirmohammadi, S. (2012). Exposure assessment of greenhouse workers with anticholinesterase pesticides by biological monitoring. Iran Occupational Health, 39(9): 1-10.

Bernama. (2018). Alarming trend of unregistered pesticides coming into Malaysia from neighbouring nations. New Straits Times. Retrieved from https://www.nst.com.my/news/nation/2018/12/437053/alarming-trend-unregisteredpesticides-coming-malaysia-neighbouring

Bertolote, J. M., Fleischmann, A., Butchart, A., \& Besbelli, N. (2006). Suicide, suicide attempts and pesticides: a major hidden public health problem.

Sulaiman, S. K. B., Ibrahim, Y., \& Jeffree, M. S. (2019). Evaluating the perception of farmers towards pesticides and the health effect of pesticides: A cross-sectional study in the oil palm plantations of Papar, Malaysia. Interdisciplinary toxicology, 12(1), 15.

Department of Agriculture. List of banned and restricted pesticide database. (2020) [Internet]. Putrajaya: Department of Agriculture, $2020 . \quad$ Available: http://www.doa.gov.my/index/resources/aktiviti_sumber/sumber_awam/maklumat_racun _perosak/pendaftaran_rmp/senarai_racun_perosak_haram_terhad.pdf. Retrieved 28 February 2021.

Greene, S. A., and Pohanish, R. P. (2005). Sitting's handbook of pesticide and agriculture chemicals ( $1^{\text {st }}$ Edition). William Andrew. 
Hillocks R. (2012). Farming with fewer pesticides: EU pesticide review and resulting challenges for UK agriculture. Crop Prot., 31: 85-93.

Kamaruzaman, N. A., Leong, Y. H., Jaafar, M. H., Khan, H. R. M., Rani, N. A. A., Razali, M. F., \& Majid, M. I. A. (2020). Epidemiology and risk factors of pesticide poisoning in Malaysia: a retrospective analysis by the National Poison Centre (NPC) from 2006 to 2015. BMJ open, 10(6), e036048.

Kim, K. H., Kabir, E., and Jahan, S. A. (2017). Exposure to pesticide and the associated human health effects. Science of The Total Environment, 575: 525-535.

Knoema. Malaysia - Pesticide regulation. VA USA: Knoema Corporation. (2019). https://knoema.com/search?query=malaysia\%20pesticide\&source=HomePage. Retrieved 28 February 2021.

Fuad, M. M., Junaidi, A. B., Habibah, A., Hamzah, J., Toriman, M. E., Lyndon, N., ... \& Azima, A. M. (2012). The impact of pesticides on paddy farmers and ecosystem. Advances in Natural and Applied Sciences, 6(1), 65-70.New Straits Times. (25 December 2018). Stop them coming in.

Praneetvatakul, S., Schreinemachers, P., Pananurak, P., and Tipraqsa, P. (2013). Pesticides, external costs and policy options for Thai agriculture. Environ Sci. Policy, 27:103-113.

Ramachandra, R., and Mourin, J. (2006). Overview of the POPs Pesticide Situation in Malaysia. Pesticide Action Network Asia and the Pacific (PAN AP).

https://ipen.org/sites/default/files/documents/1mal_pops_pesticides_in_malaysia-en.pdf. Retrieved 28 February 2021.

New Straits Times. (2018). Illegal pesticide use rampant in Cameron Highlands; toxins entering water supply

Rezaei, R., Damalas, C. A., and Abdollahzadeh, G. (2018). Understanding farmers' safety behaviour towards pesticide exposure and other occupational risks: the case of Zanjan, Iran. Science of Total Environment, 616-617: 1190-1198

Roger, P. A., Simpson, I., Oficial, R., Ardales, S., and Jimenez, R. (1994). Effects of Pesticides on Soil and Water Microflora and Mesofauna in Wetland Ricefields: A Summary of Current Knowledge and Extrapolation to Temperate Environments. Australian Journal of Experimental Agriculture., 34: 1057-68.

Summer, J. (2017). Overview of Pesticide Management in Malaysia.

https://agrochemical.chemlinked.com/chempedia/overview-pesticide-managmentmalaysia. Retrieved 28 February 2021.

The Sun Daily. (2018). Alarming trend of unregistered pesticides coming into Malaysia from neighboring nations.

The Star Online. (2019). Banned but still in use. https://www.thestar.com.my/opinion/letters/2013/02/01/banned-but-still-in-use/. Retrieved 28 February 2021.

World Health Organization. Safer access to pesticides for suicide prevention. Experiences from community interventions [Internet]. Geneva: World Health Organization, (2016). https://apps.who.int/iris/bitstream/handle/10665/246233/WHO-MSD-MER-16.3eng.pdf?sequence=1. Retrieved 28 February 2021. 